\title{
Charge separation at molecular donor-acceptor interfaces: correlation between morphology and solar cell performance
}

\author{
Andreas Opitz, Julia Wagner, Wolfgang Brütting, Ingo Salzmann, Norbert Koch, \\ Jochen Manara, Jens Pflaum, Alexander Hinderhofer, Frank Schreiber
}

\begin{abstract}
Blends of organic electron and hole conductive materials are widely used for ambipolar charge carrier transport and donor/acceptor photovoltaic cells. Thereby the efficiency of these excitonic solar cells is correlated to the morphology of the interface between the donor and the acceptor materials, which in turns depends on the preparation conditions, the crystallization of the particular materials, and the interaction between the donor and acceptor molecules. In this contribution the influence of the morphology on the solar cell architecture and performance will be discussed using different molecular donor-acceptor combinations.
\end{abstract}

\section{INTRODUCTION}

In comparison to conventional (inorganic) semiconductor photovoltaic cells, the working mechanism of their organic counterparts differs in several fundamental aspects [1], [2]. The main difference can be found in the nature of the photoexcited states. In organic solar cells the absorption of photons leads to the creation of strongly bound excitons instead of free electron-hole pairs [3]. Associated with high exciton binding energies typically in the range between $0.2 \mathrm{eV}$ and $1.5 \mathrm{eV}$ in organic semiconducting materials [4], interfacial processes play a crucial role. To account for this characteristic property, the interface morphology of OPVCs has to be well controlled.

One reason for the high binding energy can be found in the comparatively low dielectric constant of organic materials resulting in a long range of the attractive Coulomb potential between an electron-hole pair. Furthermore, weak van der Waals interactions between individual molecules lead to a spatial restriction of the electronic wave function and thus a localization of electron-hole pairs in their mutual Coulomb potential well. Substantial progress towards an efficient charge carrier separation - and with that towards efficient organic solar cells - was made in 1986 by Tang with the utilization of two organic materials with dissimilar electronic properties forming a donor-acceptor (DA) heterojunction [5]. Appropriate alignment of the energy levels of the donor and acceptor,

Manuscript received xxx; revised xxx

A. Opitz (e-mail: Andreas.Opitz@physik.uni-augsburg.de), J. Wagner, and W. Brütting (e-mail: Wolfgang.Bruetting@physik.uni-augsburg.de) are with the Institute of Physics at the University of Augsburg (Germany).

I. Salzmann and N. Koch are with the Institute of Physics at the Humboldt University of Berlin (Germany).

J. Manara and J. Pflaum are with the Institute of Physics at the University of Würzburg and with the Bavarian Center for Applied Energy Research in Würzburg (Germany).

A. Hinderhofer and F. Schreiber are with the Institute of Applied Physics at the University of Tübingen (Germany). respectively, enables successful exciton dissociation which results in a geminate pair, i.e. a Coulombically bound hole polaron in the donor and electron polaron in the acceptor material.

For such a DA interface, charge generation can be split into a four-step process as illustrated in figure 1 [6]:

1) Absorption of light and generation of excitons

2) Exciton diffusion to the interface

3) Exciton dissociation and charge carrier generation at the interface

4) Charge carrier collection at the electrodes.

The overall charge generation process is quantified by the internal quantum efficiency [6]

$$
\eta_{\mathrm{int}}=\eta_{\mathrm{Abs}} \cdot \eta_{\mathrm{ED}} \cdot \eta_{\mathrm{CT}} \cdot \eta_{\mathrm{CC}}
$$

which is the product of the absorption efficiency $\eta_{\mathrm{Abs}}$, the exciton diffusion efficiency $\eta_{\mathrm{ED}}$, the charge transfer efficiency $\eta_{\mathrm{CT}}$ and the charge collection efficiency $\eta_{\mathrm{CC}}$. If reflection losses for coupling light from outside into the cell are taken into account, one obtains the external quantum efficiency $\eta_{\text {ext }}$ which is basically the number of collected electrons with respect to the number of incident photons:

$$
\eta_{\text {ext }}=(1-R) \eta_{\text {int }}
$$

with $R$ being the reflectivity of the device.

$\eta_{\text {ext }}$ is experimentally determined by the measured current density at short-circuit conditions $\left(J_{\mathrm{SC}}\right)$ divided by the incident light intensity at a given wavelength. The overall power conversion efficiency $\eta_{\mathrm{P}}$ of a solar cell is given by

$$
\eta_{\mathrm{P}}=\frac{J_{\mathrm{SC}} \cdot V_{\mathrm{OC}} \cdot F F}{P_{\mathrm{in}}}
$$

where $V_{\mathrm{OC}}$ is the open-circuit voltage, $F F$ the fill factor and $P_{\text {in }}$ the incident optical power density, preferably measured under AM1.5 sunlight conditions.

The typically high absorption coefficients of organic semiconductors $\left(\alpha \approx 10^{5} \mathrm{~cm}^{-1}\right)$ allow for almost complete light absorption for sufficiently thick organic layers [7]. At suitable DA interfaces the charge transfer is found to occur on time scales of a few hundred femto-seconds [8] yielding high charge transfer efficiencies. Furthermore, also the charge carrier collection efficiency in a planar heterojunction (PHJ) photovoltaic cell can be close to $\eta_{\mathrm{CC}} \approx 100 \%$ if the charge carrier mobility is sufficiently high [9]. However, one of the limiting factors is given by $\eta_{\mathrm{ED}}$. The observed exciton diffusion lengths 

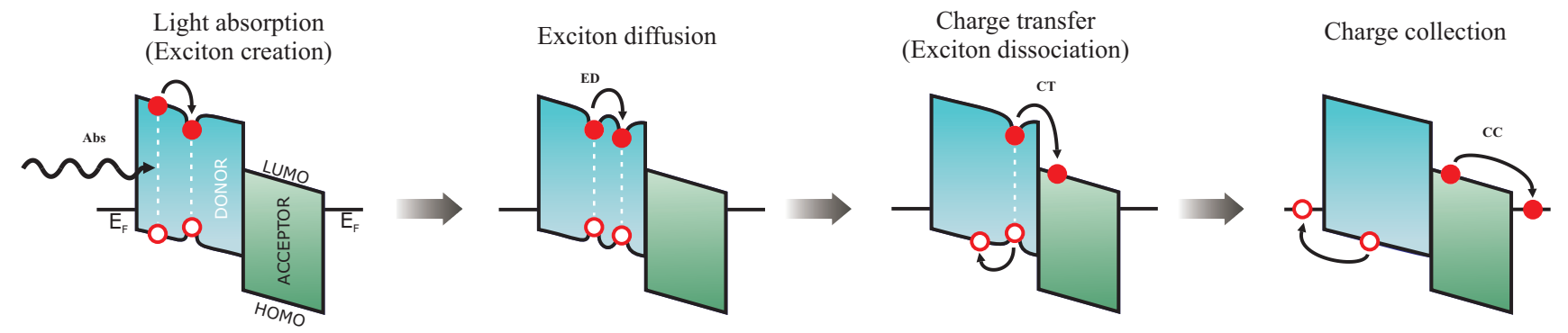

Fig. 1. Basic processes in organic solar cells related to the energy diagram of a DA cell. $E_{\mathrm{F}}$ are the Fermi energies of the cathode and anode contacts, respectively. LUMO is the lowest unoccupied molecular orbital, and HOMO is the highest occupied molecular orbital of the organic film. Filled circles represent electrons and open circles holes. A line between electron and hole symbolizes an exciton while a dip in the energy levels depicts the lowering of energy by Coulomb interaction between electron and hole. $\eta_{\mathrm{Abs}}, \eta_{\mathrm{ED}}, \eta_{\mathrm{CT}}$, and $\eta_{\mathrm{CC}}$ are the efficiencies of light absorption, exciton diffusion, charge transfer, and charge carrier collection, respectively.

are typically a few nanometers only for molecular materials [7], [10], [11], which is significantly shorter than the optical absorption length $(100-200 \mathrm{~nm})$ required for absorbing a significant fraction of the incident light [6]. To overcome this exciton diffusion bottleneck, different strategies to increase the active volume of the cell have been employed with the bulk heterojunction $(\mathrm{BHJ})$ and the multi heterojunction approach being probably the most successful ones [7], [9], [12], [13], [14]. Using these concepts, it has been demonstrated that power conversion efficiencies exceeding $5 \%$ can be achieved both with polymers and tandem cells using molecular materials [15], [16], [17].

Numerous studies on conjugated polymer/methano-fullerene blends have shown that mixing donor and acceptor materials in a BHJ cell, though being very simple in principle, can lead to significant variations in cell performance, mostly due to different film morphologies [18]. It was found that in blends of a poly(phenylenevinylene) derivative (MDMO-PPV) and the soluble fullerene derivative (PCBM) with a PCBM content exceeding 67 wt.- $\%$ a molecular dispersion with $1: 1$ stoichiometry is superimposed by a large scale interpenetrating network with pronounced percolation pathways. Recent numerical simulations show that not only the length scale of the phase separation between donor and acceptor but also the orientation of the phase separated regions with respect to the electrodes plays a crucial role [19]. It turns out that phase separated nanopillars with diameters in the range of the exciton diffusion length and growth direction perpendicular to the electrodes are most favorable for achieving low recombination losses accompanied by high charge carrier mobilities to achieve efficient charge collection.

For organic photovoltaic cells (OPVCs) based on smallmolecule materials, which are the focus of this work, there are different possible device structures under consideration: a bulk heterojunction fabricated by co-evaporation of donor and acceptor molecules [20] and the planar (multi-)heterojunction obtained by sequential evaporation of both materials [7], [21]. A further improvement of device performance could be realized by a hybrid DA heterostructure, i.e. a blend sandwiched between neat donor and acceptor layers, providing efficient exciton dissociation and simultaneously maintaining good charge carrier transport towards the electrodes [22]. In spite of the huge amount of work related to the growth of a single molecular material on various kinds of substrates, there are up to now very little systematic growth studies on molecular blends. Particularly, there is a lack of investigations of the correlation between film morphology under controlled growth conditions and microscopic processes in the corresponding solar cell. Furthermore, the number of materials for which these studies have been performed is quite limited, comprising basically only $\mathrm{Cu}$ - or $\mathrm{Zn}$-phthalocyanine combined with the fullerene $\mathrm{C}_{60}$ or perylene derivatives (e.g. PTCBI). Bilayers and blends of $\mathrm{CuPc}$ and $\mathrm{C}_{60}$ were investigated as a function of deposition conditions and layer composition [23]. An enhancement of OPV power conversion efficiency by a factor of two was obtained in going from a planar heterojunction via fully mixed blends to a structure with a compositional gradient from the pure donor material at the anode to the pure acceptor at the cathode [24]. It was shown that the morphology of CuPc:PTCBI blends can be altered by post-deposition annealing if covered with a metal electrode [9]. Furthermore, the morphologies and device performance of $\mathrm{CuPc}: \mathrm{C}_{60}$ mixtures grown by standard thermal evaporation and vapor phase deposition using gas flow were compared [25].

\section{MATERIAls AND SOlAR CELL ARCHITECTURES}

The focus of our joint studies is to address the correlation between film and interface morphology and the photoelectrical properties of molecular donor-acceptor cells. Figure 2 shows different possible architectures, where an interface for exciton dissociation is present. The simplest case is a well defined sharp interface (see figure $2 \mathrm{a}$ ) between the donor and the acceptor layer (planar heterojunction). By creating a roughened or an interdigitated layer structure (figure $2 b, c$ ) the effective interfacial area can be increased. In a bulk heterojunction the DA interface is distributed over the entire blended film either as a homogenous molecular mixture, a compositional gradient or as a (nano)phase separated system (see figure $2 \mathrm{~d}$ f). The length scale of the phase separation can be influenced by post-deposition annealing in polymer [26] and molecular [9] solar cells. Such a distributed interface allows for exciton 


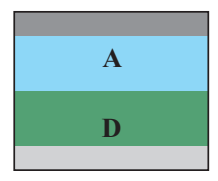

(a)

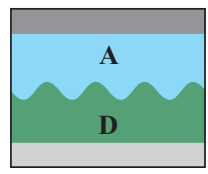

(b)

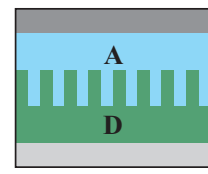

(c)

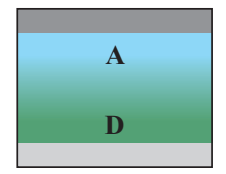

(d)

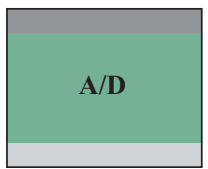

(e)

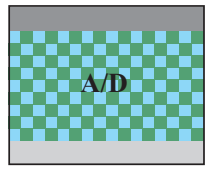

(f)

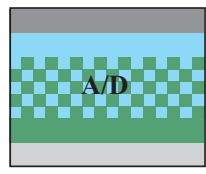

(g)

Fig. 2. Different architectures for solar cells: (a) planar heterojunction, (b) DA heterojunction with rough interface, (c) planar DA layers combined with interdigitated interface, (d) gradient heterojunction, (e) bulk heterojunction (molecular mixture), (f) phase separated bulk heterojunction, (g) planar heterojunction with mixed interface.

dissociation even if the exciton diffusion length is rather low. Furthermore, the realization of percolation pathways for unhindered transport of charge carriers to the electrodes is important. However, for optimizing the overall efficiency of a photovoltaic device it has to be taken into account that the efficiencies of the individual processes are partly connected to each other. An additional structure providing an increased DA interface in the active layer and simultaneously accounting for an efficient transport of both charge carriers to the electrodes is a PHJ with a diffuse interface, the so-called planar-mixed heterojunction (PM-HJ) (see figure $2 \mathrm{~g}$ ). The neat transport layers underneath and on top of the mixed photo-active layer prevent short-cuts between the electrodes by pathways of one material in the blend and reduce damage of the photo-active layer by deposition of the top metal contact.

It is not to be expected that all these different interface morphologies can be realized with one single DA combination. We have therefore looked at several donor and acceptor materials shown in figure 3 and have fabricated both planar and bulk heterojunction devices from different combinations of them. The chosen materials are copper phthalocyanine $(\mathrm{CuPc})$, pentacene (Pen), diindenoperylene (DIP), and sexithiophene (6T) as donor together with Buckminster fullerene $\left(\mathrm{C}_{60}\right)$, perfluorinated $\mathrm{CuPc}\left(\mathrm{F}_{16} \mathrm{CuPc}\right)$, and perfluorinated Pen (PFP) as acceptor. The motivation behind the choice of materials was that depending on the shape of the different molecular species, being spherical such as $\mathrm{C}_{60}$, disk-shaped like the CuPc's or rod-like as 6T, DIP, Pen and PFP, one could expect to observe different film growth scenarios, in particular in BHJ structures. Additionally, as indicated in figure 4 the materials cover a wide range of energy levels of their highest occupied molecular orbital (HOMO) and their lowest unoccupied molecular orbital (LUMO). Assuming vacuum level alignment at the DA interface an upper limit for the achievable open-circuit voltage $\left(V_{\mathrm{OC}}\right)$ can be estimated from the intermolecular gap, the difference between the HOMO of the donor and the LUMO of the acceptor. (Interface dipoles as reported for the $\mathrm{CuPc} / \mathrm{C}_{60}$ interface [27] are neglected in the estimation.)

A third issue to be considered is the different strength and spectral range of light absorption. Figure 5 shows absorption spectra of the used materials calculated from transmission measurements on transparent substrates. In order to increase the short-circuit current $\left(J_{\mathrm{SC}}\right)$, harvesting a large portion of the solar spectrum is important, which is particularly challenging for the red and near-infrared spectral regions. To meet this requirement the absorption spectra of donor and acceptor materials should preferably complement one another as it is the case for the donor materials $\mathrm{CuPc}$ or Pen combined with the acceptor $\mathrm{C}_{60}$. All other DA combinations show relatively large spectral overlap and thus provide less favorable conditions for high degrees of absorption over the entire solar spectrum. Furthermore, the maximum absorption coefficient in the visible part of the spectrum differs considerable among the chosen materials. This is partly due to different oscillator

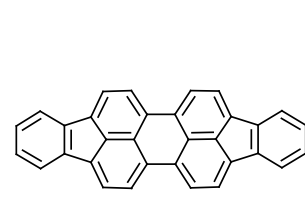

DIP

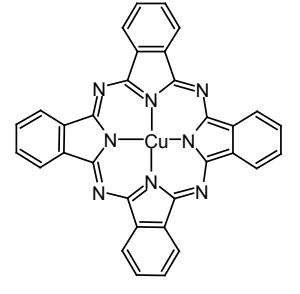

CuPc

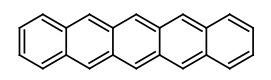

Pen

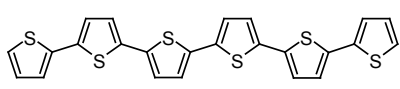

$6 \mathrm{~T}$

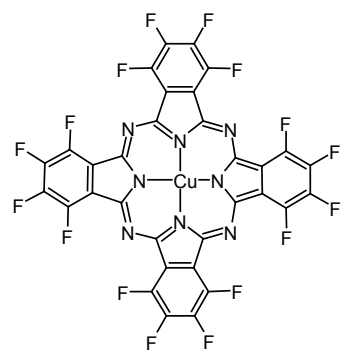

$\mathrm{F}_{16} \mathrm{CuPC}$

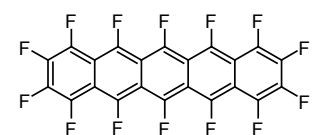

PFP

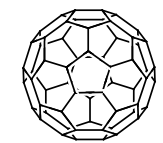

$\mathrm{C}_{60}$

Fig. 3. Chemical structures of the molecular donor materials (CuPc - copper phthalocyanine, Pen - pentacene, DIP - diindenoperylene, 6T - sexithiophene) and the molecular acceptor materials $\left(\mathrm{C}_{60}-\right.$ Buckminster fullerene, $\mathrm{F}_{16} \mathrm{CuPc}-$ perfluorinated $\mathrm{CuPc}$, PFP - perfluorinated Pen). 


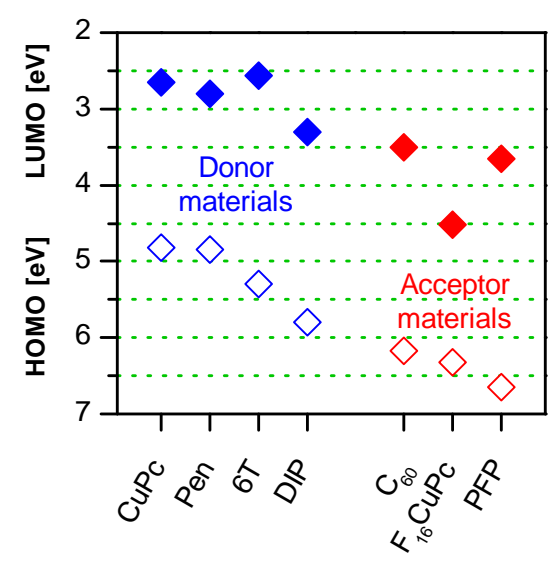

Fig. 4. Energy levels of the highest occupied molecular orbital (HOMO, filled symbols) and the lowest unoccupied molecular orbital (LUMO, open symbols) for the investigated materials. The values are taken from the literature [28], [4], [29], [30] and indicate the energy levels of the respective charge carriers. The LUMO for DIP is calculated from the HOMO [30] and the relation of the optical gap and the transport gap in reference [4]. The materials are sorted with decreasing value of the HOMO level.

strengths of the involved electronic transitions, but partly a consequence of the optical anisotropy of the materials. Especially for 6T and DIP the direction of the transition dipole moment is along the long molecular axis, which has for the consequence that films with preferentially upright standing molecules are only relatively weakly absorbing optically [31]. In contrast, pentacene shows higher absorption in spite of standing molecules because the transition dipole moment is along the short molecular axis in this case [32].

The aim of this paper is to give an overview of our ongoing work on the comparison of different solar cell architectures realized by the above mentioned material combinations. We will focus on three particular systems, namely $\mathrm{CuPc}$ and $\mathrm{C}_{60}$, pentacene with $\mathrm{C}_{60}$ and the combination of $\mathrm{CuPc}$ and its perfluorinated analogue $\mathrm{F}_{16} \mathrm{CuPc}$ as they exhibit three different prototypes of phase formation behavior in a bulk heterojunction mixture. For details on device fabrication, measurement conditions and an in-depth discussion of the results we refer to already published work [33], [34]. At the end we will present some new results on $6 \mathrm{~T} / \mathrm{C}_{60}$ and $\mathrm{DIP} / \mathrm{C}_{60}$ devices showing very promising performance as planar heterojunctions, but certainly need further investigation and optimization.

\section{INTERFACE MORPHOLOGY AND SOLAR CELL PERFORMANCE}

The results described in the following were obtained on films grown by molecular beam deposition in high vacuum. As substrate indium tin oxide (ITO) glass precoated with a thin layer $(\sim 25 \mathrm{~nm})$ of the conducting polymer PEDOT:PSS was used. Film growth was performed either with the substrate kept at room temperature or at about $100^{\circ} \mathrm{C}$ (as indicated in the respective figure captions). For device characterization an exciton blocking layer (when mentioned in the figure caption) and a counter electrode ( $\mathrm{LiF} / \mathrm{Al}, \mathrm{Al}$, or $\mathrm{Sm}$ ) was applied by thermal evaporation in a crossbar architecture yielding active device areas of about $4 \mathrm{~mm}^{2}$. Morphological characterization was performed using a scanning force microscope (SFM) under ambient conditions, while photoelectrical measurements were conducted in a nitrogen filled glove box or in a vacuum chamber. The light intensities of the simulated AM1.5 sun spectrum have been measured with a $1 \times 1 \mathrm{~cm}^{2}$ calibrated reference cell (LOT-Oriel, calibrated against NREL standard). Nevertheless, as the perfect homogeneity of the light beam cannot be guaranteed, the power conversion efficiency of cells with smaller sizes might be overestimated. No corrections accounting for spectral mismatch have been performed [35].

We would also like to note that the device performance shows some variations from sample to sample, depending on the detailed device fabrication conditions (e.g. thickness control, substrate temperature, evaporation rates). To account for this, all different device types have been repeatedly fabricated and characterized. The numbers reported later on in table I indicate the spreading of the obtained device parameters. It is also important to mention that the type of metal used for the top contact and the usage of an exciton blocking interlayer have been independently tested and optimized for each DA combination. Hence the device structures reported here are not necessarily identical for the different material systems. However, within a given DA combination we always compare planar and bulk heterojunction devices with the same stack design so that conclusions about the influence of the DA interface morphology are not severely affected by the choice of the contacts or by the presence of an exciton blocker.

\section{A. $\mathrm{CuPc}-\mathrm{C}_{60}$}

The combination of $\mathrm{CuPc}$ and $\mathrm{C}_{60}$ is a well-known molecular DA combination with favorable conditions for light-
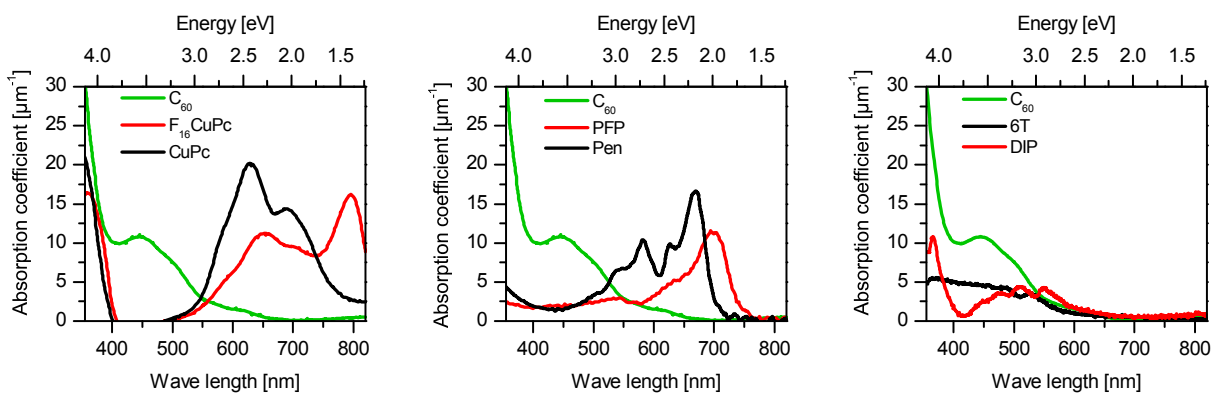

Fig. 5. Absorption spectra of the investigated materials. The spectra are calculated from transmission measurements on transparent substrates. 
a

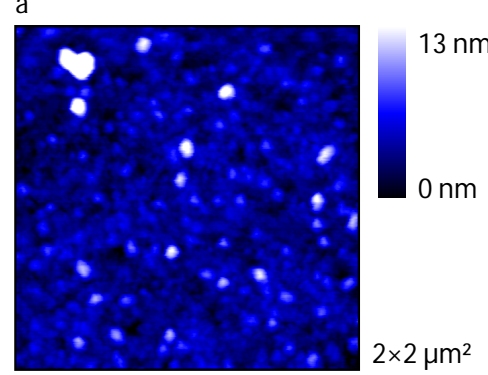

b

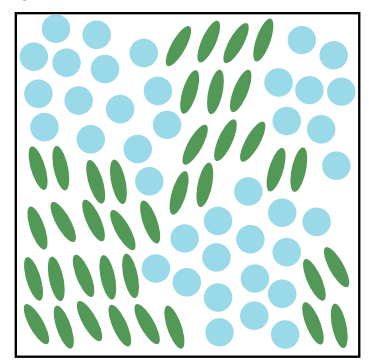

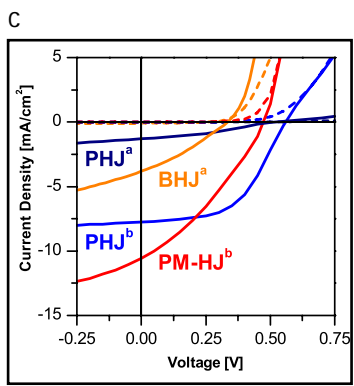

Fig. 6. Analysis of the CuPc- $\mathrm{C}_{60}$ material combination: (a) scanning force microscopy image of a $1: 1$ mixture, (b) cartoon of the morphology in this phase separated blend, (c) current-voltage characteristics of the PHJ and the BHJ (superscript a - both without an exciton blocking layer) as well as the PHJ and the PM-HJ (superscript b - both with an exciton blocking layer) in the dark and under $100 \mathrm{~mW} / \mathrm{cm}^{2}$ simulated AM1.5 illumination. The layer structure for the $\mathrm{PHJ}^{\mathrm{a}}$ is $\mathrm{ITO} / \mathrm{PEDOT}: \mathrm{PSS} / \mathrm{CuPc}(40 \mathrm{~nm}) / \mathrm{C}_{60}(40 \mathrm{~nm}) / \mathrm{LiF} / \mathrm{Al}$, for the $\mathrm{BHJ}^{\mathrm{a}}$ ITO/PEDOT:PSS/CuPc:C $60=1: 1(80 \mathrm{~nm}) / \mathrm{LiF} / \mathrm{Al}$, for the PHJ ${ }^{\mathrm{b}}$ ITO/PEDOT:PSS/CuPc $(40 \mathrm{~nm}) / \mathrm{C}_{60}(60 \mathrm{~nm}) / \mathrm{BCP}(8 \mathrm{~nm}) / \mathrm{Al}$, and for the PM-HJ ITO/PEDOT:PSS/CuPc(3.5 nm)/CuPc: $\mathrm{C}_{60}=1: 1(50 \mathrm{~nm}) / \mathrm{C}_{60}(5 \mathrm{~nm}) / \mathrm{BCP}(8 \mathrm{~nm}) / \mathrm{Al}$.

harvesting due to their complementary absorption spectra and high absorption coefficient over almost the full visible range [36]. As the absorption of the phthalocyanine (see figure 5) and the acceptor strength of the fullerene [37] are high this material combination became a model system for analyzing molecular solar cells. An external quantum efficiency of $5.0 \%$ was achieved with this system [22] in a bulk heterojunction device with adjacent neat transport layers. It was shown furthermore that by variation of the annealing temperature the microstructure can be modified to improve the solar cell efficiency [9].

Neat films of $\mathrm{CuPc}$ and $\mathrm{C}_{60}$ grow as relatively smooth layers exhibiting a polycrystalline morphology with typically needlelike crystallites for $\mathrm{CuPc}$ and more spherical grains for $\mathrm{C}_{60}$ [33]. However, if both materials are co-evaporated to form a blend, a markedly different film morphology is obtained due to the dissimilar molecular shape. Figure 6a shows an SFM image of a 1:1 blend with considerable roughness and island structures. [38], [39]. Although, the exact phase composition of these features remains to be determined, a plausible explanation of this morphological observation is given by a phaseseparation resulting in nano-scaled grains of each material. Figure $6 \mathrm{~b}$ displays a simplified schematic of the suggested morphology inside these blends, assuming that both materials are not miscible. Recently, evidence for phase separation in CuPc: $\mathrm{C}_{60}$ blends was reported from X-ray scattering [33]. The mixed film shows the same Bragg peak positions as layers of the neat materials corresponding to the $\alpha$-phase of $\mathrm{CuPc}$ and the fcc-structure of $\mathrm{C}_{60}$. This fact can be traced back to the simultaneous existence of $\mathrm{CuPc}$ and $\mathrm{C}_{60}$ crystallites in the blend. Nevertheless, we would like to mention that also featureless SFM images for these mixtures have been reported in the literature [24], reflecting probably slightly different film growth conditions in different laboratories.

Charge transport properties of mixed films have previously been investigated in field-effect transistors [40], [41] and photodiodes [42], [33]. Both electron and hole mobilities were found to decrease exponentially in blends with decreasing content of the electrically conducting molecular species. This is in full agreement with the picture of nano-phase separation resulting in charge carrier transport by percolation through the respective pathways of each species.

The performance of this material combination has been studied in photovoltaic cells utilizing either a planar heterojunction or a bulk heterojunction (1:1 blend). Typical currentvoltage characteristics in the dark and under simulated AM1.5 conditions are depicted in figure $6 \mathrm{c}$ and the photovoltaic parameters are given in table I. Furthermore the characteristics of a planar heterojunction and a planar-mixed heterojunction with an exciton blocking layer of BCP are shown. As general observation we find in cells with mixed layers (BHJ and $\mathrm{PM}-\mathrm{HJ}$ ) higher short circuit currents $J_{\mathrm{SC}}$ in comparison to the respective planar heterojunctions, indicating more efficient exciton dissociation due to an increased interfacial area [42], [33]. Unfortunately, this benefit is accompanied by a decrease in the open-circuit voltage $V_{\mathrm{OC}}$ e.g. from $0.56 \mathrm{~V}$ for the $\mathrm{PHJ}$ cell to $0.49 \mathrm{~V}$ for the PM-HJ cell. $V_{\mathrm{OC}}$ is mainly defined by the intermolecular gap between the LUMO of the acceptor and the HOMO of the donor. Earlier studies of this material combination showed a reduced intermolecular gap in blended films [43], [42]. Additionally, coupling of the quasi Fermilevels in the blend to the electrode materials is different for the bulk and planar heterojunctions [44]. The low FF in the PM$\mathrm{HJ}$ may partly be assigned to inappropriate layer thicknesses and subsequently high series resistance [24]. Also for other molecular materials it was shown that the fill factor in solar cells containing blended films is lower than in planar heterojunction cells [45]. The layer thickness of the organic blend might exceed the thickness in which percolation pathways reach the electrodes from the whole volume of the device. The current-voltage characteristics of the PHJ device without an exciton blocking layer is affected by an S-shape behavior, i.e. a low current density near and above $V_{\mathrm{OC}}$ which reduces $F F$. The appearance of this undesired feature has recently gained more and more attention in the literature. Uhrich et al. could relate the S-shaped current-voltage characteristics to insufficient energy level alignment between the photoactive layer system and the hole transport layer of a PHJ device. An accumulation of charge carriers inside the device leads to suppressed forward current as well as reduced photocurrent in the vicinity of $V_{\mathrm{OC}}$ [44]. A similar explanation of the "kink" in the current-voltage curve close to $V_{\mathrm{OC}}$ was given by Nelson et al. 
a

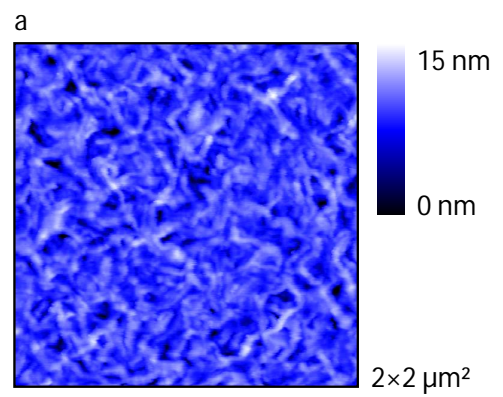

b

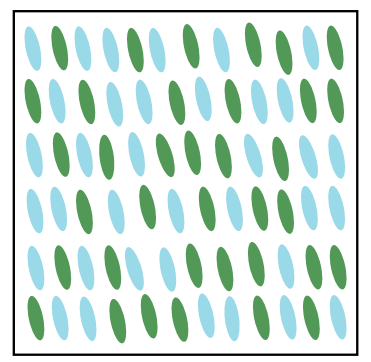

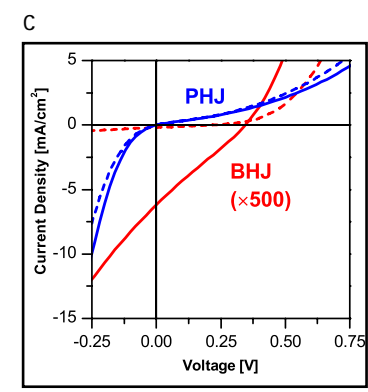

Fig. 7. Analysis of the $\mathrm{CuPc}-\mathrm{F}_{16} \mathrm{CuPc}$ material combination: (a) scanning force microscopy image of a $1: 1$ mixture, (b) cartoon of the morphology in this molecularly mixed blend, (c) current-voltage characteristics of the $\mathrm{PHJ}$ and the $\mathrm{BHJ}$ in the dark and under $100 \mathrm{~mW} / \mathrm{cm}^{2}$ simulated AM1.5 illumination. The layer structure for the PHJ is ITO/PEDOT:PSS/CuPc $(40 \mathrm{~nm}) / \mathrm{F}_{16} \mathrm{CuPc}(40 \mathrm{~nm}) / \mathrm{LiF}(0.5 \mathrm{~nm}) / \mathrm{Al}$ and for the $\mathrm{BHJ}$ ITO/PEDOT:PSS/CuPc:F ${ }_{16} \mathrm{CuPc}=1: 1(80 \mathrm{~nm}) / \mathrm{LiF}(0.5 \mathrm{~nm}) / \mathrm{Al}$.

Based on a simple model of a molecular photovoltaic device as a two-level, light absorbing system the S-shaped characteristic was connected to slow charge transfer originating from large energy steps at the electrodes [46]. Furthermore, degradation studies on pentacene/ $\mathrm{C}_{60}$ heterojunction solar cells related the deterioration of device performance - manifested in a continuous decrease of $F F$ - with photooxidation and UV annealing [47]. The effect is explained by the reorganization of pentacene near the ITO substrate resulting in an ITO/pentacene interface barrier. The responsibility of interfaces for the $\mathrm{S}$ shaped characteristics is also confirmed by Kumar et al.[48] and Glatthaar et al.[49], ascribing this anomalous feature to a charge extraction barrier as a result of interfacial dipoles [48] and a hindered charge transfer at one of the electrical contacts caused by the corrosion of the contact metal, respectively.

Compared to similarly structured solar cells based on $\mathrm{CuPc} / \mathrm{C}_{60}$ [50] our OPVCs show lower power conversion efficiencies although an exciton blocking layer bathocuproine (BCP) is used which prohibits quenching of excitons at the electrode [51], [52], [53], [54]. The reason may be found in not optimized layer thicknesses. Optimization of this parameter is indispensable for high efficiencies of exciton diffusion and charge carrier collection and to exploit optical interference effects inside the device [36]. Nevertheless, a free variation of the film thicknesses is partially limited as the rough morphology of the organic layers requires sufficiently thick films to avoid undesirable leakage in the current-voltage measurement.

\section{B. $\mathrm{CuPc}-\mathrm{F}_{16} \mathrm{CuPc}$}

Fluorination of organic molecules is a well-known method to tune the electrochemical potentials of a material towards higher electron affinity and ionization potential, leaving the energy gap of the phthalocyanines more or less unaffected [55], [56]. In this way a donor-type material (such as $\mathrm{CuPc}$ ) can be turned into an electron acceptor. We have therefore studied bilayers and blends of the $\mathrm{H}$-terminated $\left(\mathrm{H}_{16^{-}}\right) \mathrm{CuPc}$ with its fully fluorinated analogue $\mathrm{F}_{16} \mathrm{CuPc}$. In contrast to the above discussed system both materials are structurally very similar (disk-shape) so that a completely different film growth scenario and phase behavior could be expected in their mixtures.

Blends of CuPc: $\mathrm{F}_{16} \mathrm{CuPc}$ show the same SFM morphology as the neat films of $\mathrm{CuPc}$ and $\mathrm{F}_{16} \mathrm{CuPc}$ (see figure $7 \mathrm{a}$ and ref. [57]). Due to similar size and shape of both molecules and very similar packing motifs in neat crystalline films of each material they are able to form a molecularly mixed crystalline structure [57]. Thereby the lattice spacing of the blend is in between the values for the neat films. A similar scenario was observed for Pen/PFP [58] and other rodlike molecules [59], such as sexithiophene (6T), sexiphenyl (6P) and dihexylsexithiophene (DH6T). A schematic sketch illustrating the morphological concept of a molecularly mixed phthalocyanine film is presented in figure $7 \mathrm{~b}$. This molecular packing characterized by an alloy of two materials with different energy levels in alternating DA stacks leads to an electrical transport behavior markedly different to that of phase separated blends. We find that unipolar electron and hole transport is possible in these molecularly mixed films, however, if both carrier types are injected at the same time (or are photogenerated by light absorption) the current decreases by several orders of magnitude [57]. A conclusive explanation can be found in the formation of charge transfer states with a hole located at the $\mathrm{CuPc}$ molecule and an electron sitting on the neighboring $\mathrm{F}_{16} \mathrm{CuPc}$ molecule. Such a charge transfer state is unaffected by the electric field and the involved molecules are subsequently blocked for a further charge carrier transport.

This behavior leads to very low photocurrents in the BHJ solar cell as shown by the current-voltage characteristics in figure 7c. Also included in this figure are the $J-V$ characteristics for a PHJ device of both materials. Interestingly, for this device the current under reverse biasing is much higher than under forward bias conditions. This is related to the formation of a charge generation layer at the DA interface where charge carrier pairs are generated by tunneling of electrons from the $\mathrm{HOMO}$ of $\mathrm{CuPc}$ into the LUMO of $\mathrm{F}_{16} \mathrm{CuPc}$ [60]. However, for the PHJ there is almost no effect of illumination as manifested in a negligible value of $V_{\mathrm{OC}}$.

The overall performance of this material combination in photovoltaic cells is very poor. Apart from the small opencircuit voltage (which was to be expected already from the energy level diagram in figure 4) the extremely low photocurrents in blends make them useless as active layer in OPV applications. The general lessons to be learned is that this type of mixed crystalline films of donor and acceptor molecules 
a

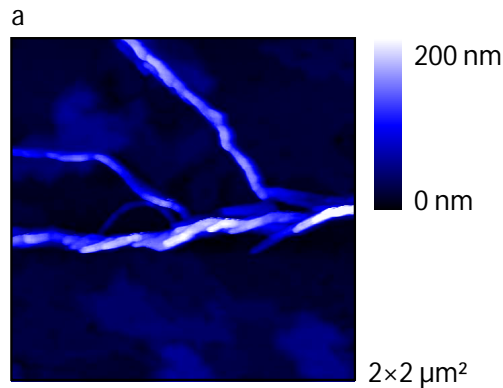

b

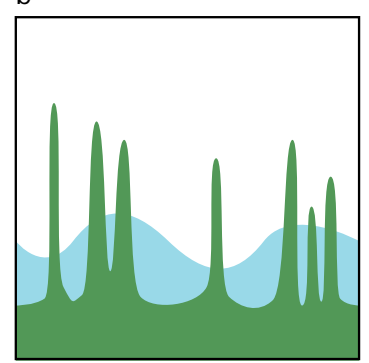

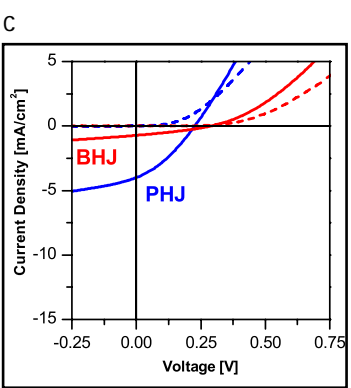

Fig. 8. Analysis of the Pen- $\mathrm{C}_{60}$ material combination: (a) scanning force microscopy image of a 1:1 mixture, (b) cartoon of the morphology with a large scale phase separation (different scale as in figures 6 and 7), (c) current-voltage characteristics of the PHJ and the PM-HJ in the dark and under halogen lamp illumination. The layer structure for the $\mathrm{PHJ}$ is ITO/PEDOT:PSS/Pen $(50 \mathrm{~nm}) / \mathrm{C}_{60}(50 \mathrm{~nm}) / \mathrm{Sm}$ and for the PM-HJ ITO/PEDOT:PSS/Pen $(5 \mathrm{~nm}) / \mathrm{Pen}: \mathrm{C}_{60}=1: 1(60 \mathrm{~nm}) / \mathrm{C}_{60}(5 \mathrm{~nm}) / \mathrm{Sm}$.

is not desirable for efficient OPV cells as it prevents charge carrier separation. (The same scenario is by the way found in Pen/PFP [58].)

\section{Pen- $C_{60}$}

Pentacene is one of the most intensively studied organic semiconductor materials, mainly due to its high charge carrier mobilities observed in organic FETs [61]. However, in the context of OPV devices there is comparatively little work reported in the literature on planar heterojunctions [62], [63], [47], although from the viewpoint of optical absorption the combination with $\mathrm{C}_{60}$ should be quite promising.

The surface morphology of co-evaporated Pen: $\mathrm{C}_{60}$ films deposited on top of a Pen pre-coverage determined by SFM is depicted in figure 8a. Together with X-ray scattering it was shown that - similar to the $\mathrm{CuPc} / \mathrm{C}_{60}$ system - phase separation takes place [34], however, in contrast to the former system the length scale is much larger in this case due to the strong crystallization tendency of pentacene. A schematic of the resulting morphology with pentacene crystallites extending beyond the $\mathrm{C}_{60}$ layer is shown in figure $8 \mathrm{~b}$. A detailed analysis of the mobility is pending but due to the large scale phase separation no strong influence on the charge carrier transport is expected as compared to neat films.

The characteristics of the PHJ and PM-HJ solar cells are shown in figure $8 \mathrm{c}$. In contrast to the $\mathrm{CuPc} / \mathrm{C}_{60}$ system the behavior of $J_{\mathrm{SC}}$ and $V_{\mathrm{OC}}$ is different in planar and bulk heterojunctions. Here the PM-HJ has the higher open-circuit voltage but a lower short circuit current. However, it seems to be obvious that large scale phase separation and the formation of large pentacene crystals are not favorable for solar cell performance. The observed pentacene needles extending through the $\mathrm{C}_{60}$ layer can lead to leakage. Additionally, the distance between the needle-like Pen islands is on the length scale of micrometers and thus far too big in comparison to the observed exciton diffusion length in $\mathrm{C}_{60}$, which further limits efficient exciton dissociation.

\section{D. $D I P / C_{60}$ and $6 T / C_{60}$}

Besides the widely-spread and intensively studied materials $\mathrm{CuPc}$ and Pen, we have recently started investigations on two rather uncommon molecular donor materials: sexithiophene
(6T) and diindenoperylene (DIP). Both materials have been used in combination with $\mathrm{C}_{60}$ as acceptor. Structural formulas, energy levels and absorption spectra are depicted in figure 35. Detailed studies on structure, morphology, charge carrier mobility and especially their correlation with solar cell performance are currently under work. Absorption coefficients are comparatively low in both materials (see figure 5) which can be attributed to predominantly upright standing molecules proven by X-ray scattering measurements and predicted by various structural investigations [64], [65], [66]. Although this leads to an unfavorable orientation of the optical transition dipole regarding the absorption of incoming light, we have observed remarkably high power conversion efficiencies already in simple planar heterojunctions. We therefore expect that these materials could hold further potential for efficient solar cells.

Up to now, DIP has not yet been investigated in organic solar cells. Recently, a similarly constructed molecule tetraphenyldibenzoperiflanthene (DBP) was used in PHJ organic solar cells exhibiting power conversion efficiencies of up to $3.6 \%$ [67]. The high $V_{\mathrm{OC}}$ and $J_{\mathrm{SC}}$ of the DBP-based cell is attributed to its high HOMO level and the effective light absorption, respectively. The latter argument cannot be applied in the case of DIP which shows quite low absorption coefficient - at least compared to CuPc and Pen - and has strong spectral overlap with $\mathrm{C}_{60}$. Furthermore, DIP has been
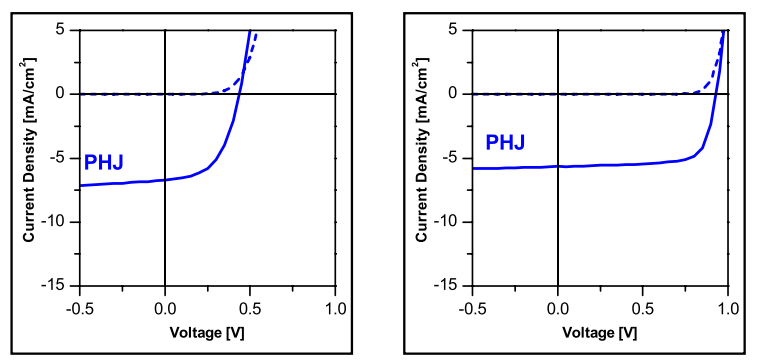

Fig. 9. Device characteristics for $6 \mathrm{~T} / \mathrm{C}_{60}$ and $\mathrm{DIP} / \mathrm{C}_{60}$ planar heterojunction solar cells in the dark and under $100 \mathrm{~mW} / \mathrm{cm}^{2}$ simulated AM1.5 illumination. The layer structure for the PHJs are ITO/PEDOT:PSS/6T $(50 \mathrm{~nm}) / \mathrm{C}_{60}(60 \mathrm{~nm}) / \mathrm{Al}$ and ITO/PEDOT:PSS/DIP $(50 \mathrm{~nm}) / \mathrm{C}_{60}(80 \mathrm{~nm}) / \mathrm{BCP}(8 \mathrm{~nm}) / \mathrm{Al}, \quad$ respectively. The DIP layer was evaporated at $100^{\circ} \mathrm{C}$ substrate temperature. 
shown to have balanced charge carrier transport along the $c^{\prime}$ direction in single crystals [68] and remarkably high exciton diffusion lengths of $\approx 100 \mathrm{~nm}$ [69]. Even though the absolute values are actually discussed in the literature [7], [10], [11], [69] a correlation between structural coherence length and exciton diffusion length is reasonable, meaning that better film crystallinity should give rise to higher exciton diffusion length [70]. A detailled study of DIP film growth on OPV relevant substrates, the resulting morphology and its relation to device performance is currently under way and will be reported elsewhere [71].

The theoretical maximum value of $V_{\mathrm{OC}}$ is a function of the difference between HOMO of the donor and LUMO of the acceptor, minus the binding energy of the dissociated, geminate electron-hole pair [72]. Thus, from the compilation of the molecular energy levels in figure 4 we expect a high $V_{\mathrm{OC}}$ for the combination of DIP with $\mathrm{C}_{60}$, which was approved by current-voltage characteristics (see figure 9). Together with a nearly rectangular shape of the $J-V$ curve, resulting in a high $F F$ reaching up to $74 \%$, power conversion efficiencies of $3.9 \%$ under $100 \mathrm{~mW} / \mathrm{cm}^{2}$ illumination were achieved. The photovoltaic parameters are given in table I to compare the different material combinations.

Sexithiophene has been used as donor material in BHJ solar cells already in 1997 [73], where blends of 6T and $\mathrm{C}_{60}$ exhibited microphase-separated morphology as revealed by transmission electron microscopy studies. More efficient BHJ solar cells of the same material combination have been reported recently by Alem et al., reaching $\eta=1 \%$ after reverse bias annealing [74]. As in the case of DIP, 6T molecules are standing upright on the substrate and thus have rather low absorption coefficients as well as a large spectral overlap with the absorption spectrum of $\mathrm{C}_{60}$, both providing a priori unfavourable conditions for efficient light harvesting.

As was expected from energy level alignment, $V_{\mathrm{OC}}$ of $6 \mathrm{~T} / \mathrm{C}_{60} \mathrm{PHJ}$ solar cells is lower than for DIP/C 60 cells (see figure 9). Nevertheless, relatively high short-circuit current densities and high fill factors lead to efficiencies of up to $1.5 \%$. Reasonable photocurrents have also been observed in
PHJ cells with thick 6T layers $(400-500 \mathrm{~nm})$, which indicate that the exciton diffusion length might be considerably larger as compared to that of CuPc. So there is room for significant further improvement by either controlling the molecular orientation or by a systematic layer thickness variation, thereby matching light absorption, exciton diffusion and charge carrier extraction lengths.

\section{SUMMARY AND OUTLOOK}

In this contribution we give an overview of our work on growth and photovoltaic characterization of different molecular donor-acceptor systems. Apart from planar heterojunctions, which have been fabricated for all DA combinations, we have particularly looked at the phase behavior and the resulting morphology of bulk heterojunctions between selected materials. Owing to the differences in molecular shape we have been able to prepare and identify three different growth scenarios leading to largely different interface morphologies and observed their consequences for device performance. Blends of $\mathrm{CuPc}$ and $\mathrm{C}_{60}$ show nano-phase separation on a length-scale of a few ten nanometers being spatially separated not too far from the expected exciton diffusion range. Additionally this system shows very favourable spectral properties for light harvesting over the whole visible range. However, we also have seen limitations in the transport properties of this material system leading to low fill factors and $\mathrm{S}$-shaped $J-V$ characteristics, in particular in $\mathrm{PHJ}$ devices. The combination of $\mathrm{CuPc}$ with its perfluorinated analogue $\mathrm{F}_{16} \mathrm{CuPc}$ leads to the formation of a molecularly mixed "organic alloy". However, such an intimate mixing is not favourable for charge separation in photovoltaic cells as the primarily formed charge-transfer states are Coulombically bound. The mixing behavior of $\mathrm{Pen} / \mathrm{C}_{60}$ represents the other extreme case exhibiting phase separation on a very large length scale (larger than the nominal layer thickness). In addition to the obvious mismatch of the resulting interface morphology with the exciton diffusion length, these large Pen crystallites lead to undesired leakage pathways for charge carriers.

Apart from these classical material systems, we have recently started investigating planar heterojunctions of DIP and

TABLE I

COLLECTION OF THE DETERMINED POWER CONVERSION EFFICIENCIES, OPEN-CIRCUIT VOLTAGES, FILL FACTORS AND SHORT-CIRCUIT CURRENT DENSITIES OF THE INVESTIGATED SOLAR CELLS. THE GIVEN RANGES INDICATE THE SPREADING OF THE OBTAINED DEVICE PARAMETERS FOR SAMPLES PREPARED UNDER COMPARABLE PREPARATION CONDITIONS. EXCEPT FOR PEN/C 60 , THE ILLUMINATION WAS SIMULATED AM1.5 SUNLIGHT CONDITIONS WITH $100 \mathrm{MW} / \mathrm{CM}^{2}$.

\begin{tabular}{|c|c|c|c|c|c|c|}
\hline \multicolumn{2}{|c|}{ Solar cell } & \multicolumn{2}{|r|}{$\eta[\%]$} & \multirow{2}{*}{$\frac{V_{\mathrm{OC}}[\mathrm{V}]}{0.50-0.53}$} & \multirow{2}{*}{$\begin{array}{c}F F[\%] \\
26-32\end{array}$} & \multirow{2}{*}{$\frac{J_{\mathrm{SC}}\left[\mathrm{mA} / \mathrm{cm}^{2}\right]}{1.2-4.0}$} \\
\hline $\mathrm{CuPc} / \mathrm{C}_{60}$ & PHJ & (without blocking layer) & $0.2-0.7$ & & & \\
\hline $\mathrm{CuPc}: \mathrm{C}_{60}$ & BHJ & (without blocking layer) & $0.3-0.9$ & $0.35-0.46$ & $31-37$ & $4.1-6.8$ \\
\hline $\mathrm{CuPc}: \mathrm{C}_{60}$ & PHJ & (with blocking layer) & $1.3-2.3$ & $0.50-0.56$ & $34-55$ & $5.5-7.7$ \\
\hline CuPc: $\mathrm{C}_{60}$ & PM-HJ & (with blocking layer) & $0.9-1.8$ & $0.48-0.55$ & $22-33$ & $7.4-10.6$ \\
\hline $\mathrm{CuPc} / \mathrm{F}_{16} \mathrm{CuPc}$ & PHJ & & \multicolumn{4}{|c|}{ no photocurrent } \\
\hline $\mathrm{CuPc}: \mathrm{F}_{16} \mathrm{CuPc}$ & BHJ & & $<0.01$ & 0.36 & 23 & 0.012 \\
\hline $\mathrm{DIP} / \mathrm{C}_{60}$ & PHJ & & $2.8-3.9$ & $0.88-0.94$ & $60-74$ & $4.6-5.4$ \\
\hline $6 \mathrm{~T} / \mathrm{C}_{60}$ & PHJ & & $1.0-1.6$ & $0.41-0.49$ & $39-59$ & $5.0-10.5$ \\
\hline $\mathrm{Pen} / \mathrm{C}_{60}$ & $\mathrm{PHJ}^{a}$ & & - & $0.22-0.25$ & $28-33$ & $1.4-2.8$ \\
\hline Pen: $\mathrm{C}_{60}$ & ${\mathrm{PM}-\mathrm{HJ}^{a}}^{a}$ & & - & $0.28-0.29$ & $26-31$ & $0.7-0.9$ \\
\hline
\end{tabular}

${ }^{a}$ non calibrated light source 
6T with the acceptor $\mathrm{C}_{60}$. These donor materials are wellknown to form highly ordered thin films with excellent charge transport properties. However, due to their tendency to grow in a fashion where the molecules are standing almost upright on the substrate and the fact that the transition dipole moment is oriented along the long axis of the molecule, their optical absorption is by far weaker than for example in CuPc and Pen. Nevertheless, first results are very promising already in PHJ devices with non-optimized layer thicknesses. In particular $\mathrm{DIP} / \mathrm{C}_{60}$ with an open-circuit voltage of $0.9 \mathrm{~V}$ and a fill factor of more than $70 \%$ has the potential for high-efficiency photovoltaic cells.

To conclude, the route towards high-efficiency molecular solar cells still holds many challenges. Phase behavior and morphology formation in molecular blends is still not very well understood, and it is obvious that the vision of tailoring interface morphologies as indicated in figure 2 is not straightforward and for sure not possible with one single material combination only. Besides molecular self-assembly and thermodynamically driven phase separation followed so far, there are currently increasing efforts to create artificial phase separation following the scenarios sketched in figure 2(b) and (c) by glancing angle deposition [75] or by stamping techniques [76], [77]. Additionally, the search for well-ordered materials with better charge and exciton transport properties could be a viable alternative to the bulk heterojunction concept.

\section{ACKNOWLEDGMENT}

This work was supported by the German Research Foundation within the Priority Program 1355 ('Elementary Processes of Organic Photovoltaics").

\section{REFERENCES}

[1] C. J. Brabec, V. Dyakonov, J. Parisi, and N. S. Sariciftci, Organic Photovoltaics. Springer, Berlin, 2003.

[2] B. A. Gregg and M. C. Hanna, "Comparing organic to inorganic photovoltaic cells: Theory, experiment, and simulation," J. Appl. Phys., vol. 93, pp. 3605-3614, 2003.

[3] B. A. Gregg, "The photoconversion mechanism of excitonic solar cells," MRS Bullettin, vol. 30, pp. 20-22, 2005.

[4] P. I. Djurovich, E. I. Mayo, S. R. Forrest, and M. E. Thompson, "Measurement of the lowest unoccupied molecular orbital energies of molecular organic semiconductors," Org. Electron., vol. 10, pp. 515$520,2009$.

[5] C. W. Tang, "Two-layer organic photovoltaic cell," Appl. Phys. Lett., vol. 48, pp. $183-185,1986$.

[6] S. Forrest, "The limits to organic photovoltaic cell efficiency," MRS Bull., vol. 30, pp. 28-32, 2005.

[7] P. Peumans, A. Yakimov, and S. R. Forrest, "Small molecular weight organic thin-film photodetectors and solar cells," J. Appl. Phys., vol. 93, pp. 3693-3723, 2003.

[8] P. A. van Hal, R. A. J. Janssen, G. Lanzani, G. Cerullo, M. ZavelaniRossi, and S. D. Silvestri, "Full temporal resolution of the two-step photoinduced energy-electron transfer in a fullerene-oligothiophenefullerene triad using sub-10 fs pump-probe spectroscopy," Chem. Phys. Lett., vol. 345, pp. 33-38, 2001.

[9] P. Peumans, S. Uchida, and S. Forrest, "Efficient bulk heterojunction photovoltaic cells using small-molecular-weight organic thin films," Nature, vol. 425, pp. 158-162, 2003.

[10] S.-B. Rim and P. Peumans, "The effects of optical interference on exciton diffusion length measurements using photocurrent spectroscopy," J. Appl. Phys., vol. 103, p. 124515, 2008.

[11] R. R. Lunt, N. C. Giebink, A. A. Belak, J. B. Benziger, and S. R. Forrest, "Exciton diffusion lengths of organic semiconductor thin films measured by spectrally resolved photoluminescence quenching," J. Appl. Phys., vol. 105, p. 053711, 2009.
[12] J. J. M. Halls, C. A. Walsh, N. C. Greenham, E. A. Marseglia, R. H Friend, S. C. Moratti, and A. B. Holmes, "Efficient photodiodes from interpenetrating polymer networks," Nature, vol. 376, pp. 498-500, 1995.

[13] G. Yu, J. Gao, J. C. Hummelen, F. Wudl, and A. J. Heeger, "Polymer photovoltaic cells - enhanced efficiencies via a network of internal donoracceptor heterojunctions," Science, vol. 270, pp. 1789-1791, 1995.

[14] C. Brabec, N. Sariciftci, and J. Hummelen, "Plastic solar cells," Adv. Funct. Mater, vol. 11, pp. 15-26, 2001.

[15] M. A. Green, K. Emery, Y. Hishikawa, and W. Warta, "Solar Cell Efficiency Tables (Version 33)," Prog. Photovoltaics, vol. 17, pp. 85-94, 2009.

[16] B. Kippelen and J.-L. Bredas, "Organic photovoltaics," Energy Environ. Sci., vol. 2, pp. 251-261, 2009.

[17] G. Dennler, M. C. Scharber, and C. J. Brabec, "Polymer-Fullerene BulkHeterojunction Solar Cells," Adv. Mater., vol. 21, pp. 1323-1338, 2009.

[18] J. van Duren, X. Yang, J. Loos, C. Bulle-Lieuwma, A. Sieval, J. Hummelen, and R. Janssen, "Relating the morphology of poly(p-phenylene vinylene)/methanofullerene blends to solar-cell performance," Adv. Funct. Mater., vol. 14, pp. 425-434, 2004.

[19] R. A. Marsh, C. Groves, and N. C. Greenham, "A microscopic model for the behavior of nanostructured organic photovoltaic devices," J. Appl. Phys., vol. 101, p. 083509, 2007.

[20] J. Rostalski and D. Meissner, "Monochromatic versus solar efficiencies of organic solar cells," Sol. Energy Mater. Sol. Cell., vol. 61, pp. 87-95, 2000 .

[21] B. Maennig, J. Drechsel, D. Gebeyehu, P. Simon, F. Kozlowski, A. Werner, F. Li, S. Grundmann, S. Sonntag, M. Koch, K. Leo, M. Pfeiffer, H. Hoppe, D. Meissner, N. Sariciftci, I. Riedel, V. Dyakonov, and J. Parisi, "Organic p-i-n solar cells," Appl. Phys. A - Mater., vol. 79, pp. 1-14, 2004.

[22] J. Xue, B. Rand, S. Uchida, and S. Forrest, "A hybrid planar-mixed molecular heterojunction photovoltaic cell," Adv. Mater, vol. 17, pp. 66-71, 2005.

[23] P. Sullivan, S. Heutz, S. M. Schultes, and T. S. Jones, "Influence of codeposition on the performance of $\mathrm{CuPc}-\mathrm{C}_{60}$ heterojunction photovoltaic devices," Appl. Phys. Lett., vol. 84, pp. 1210-1212, 2004.

[24] S. Heutz, P. Sullivan, B. M. Sanderson, S. M. Schultes, and T. S. Jones, "Influence of molecular architecture and intermixing on the photovoltaic, morphological and spectroscopic properties of $\mathrm{CuPc}_{-} \mathrm{C}_{60}$ heterojunctions," Sol. Ener. Mater. Sol. Cell., vol. 83, pp. 229-245, 2004.

[25] F. Yang, M. Shtein, and S. R. Forrest, "Morphology control and material mixing by high-temperature organic vapor-phase deposition and its application to thin-film solar cells," J. Appl. Phys., vol. 98, p. 014906, 2005.

[26] C. Mueller, T. A. M. Ferenczi, M. Campoy-Quiles, J. M. Frost, D. D. C. Bradley, P. Smith, N. Stingelin-Stutzmann, and J. Nelson, "Binary organic photovoltaic blends: A simple rationale for optimum compositions," Adv. Mater, vol. 20, pp. 3510-3515, 2008.

[27] O. V. Molodtsova and M. Knupfer, "Electronic properties of the organic semiconductor interfaces $\mathrm{CuPc} / \mathrm{C}_{60}$ and $\mathrm{C}_{60} / \mathrm{CuPc}$," J. Appl. Phys., vol. 99, p. 053704, 2006.

[28] S. Krause, M. B. Casu, A. Schöll, and E. Umbach, "Determination of transport levels of organic semiconductors by UPS and IPS," New J. Phys., vol. 10, p. 085001, 2008.

[29] M. L. Tang, A. D. Reichardt, P. Wei, and Z. Bao, "Correlating Carrier Type with Frontier Molecular Orbital Energy Levels in Organic Thin Film Transistors of Functionalized Acene Derivatives," J. Am. Chem. Soc., vol. 131, pp. 5264-5273, 2009.

[30] N. Koch, A. C. Dürr, J. Ghijsen, R. L. Johnson, J. J. Pireaux, J. Schwartz, F. Schreiber, H. Dosch, and A. Kahn, "Optically induced electron transfer from conjugated organic molecules to charged metal clusters," Thin solid films, vol. 441, pp. 145-149, 2003.

[31] U. Heinemeyer, R. Scholz, L. Gisslén, M. I. Alonso, J. O. Ossó, M. Garriga, A. Hinderhofer, M. Kytka, S. Kowarik, A. Gerlach, and F. Schreiber, "Exciton-phonon coupling in diindenoperylene thin films," Phys. Rev. B, vol. 78, p. 085210, 2008.

[32] A. Hinderhofer, U. Heinemeyer, A. Gerlach, S. Kowarik, R. M. J. Jacobs, Y. Sakamoto, T. Suzuki, and F. Schreiber, "Optical properties of pentacene and perfluoropentacene thin films," J. Chem. Phys., vol. 127, p. 194705,2007

[33] A. Opitz, J. Wagner, M. Bronner, W. Brütting, A. Hinderhofer, and F. Schreiber, "Molecular semiconductor blends: microstructure, charge carrier transport and application in photovoltaic cells," phys. stat. sol. (a), vol. 206, pp. 2683-2694, 2009. 
[34] I. Salzmann, S. Duhm, R. Opitz, R. L. Johnson, J. P. Rabe, an N. Koch, "Structural and electronic properties of pentacene-fullerene heterojunctions," J. Appl. Phys., vol. 104, p. 114518, 2008.

[35] V. Shrotriya, G. Li, Y. Yao, T. Moriarty, K. Emery, and Y. Yang, "Accurate measurement and characterization of organic solar cells," Adv. Funct. Mater, vol. 16, pp. 2016-2023, 2006.

[36] T. Stübinger and W. Brütting, "Exciton diffusion and optical interference in organic donor-acceptor photovoltaic cells," J. Appl. Phys., vol. 90, pp. 3632-3641, 2001.

[37] B. Kraabel, D. McBranch, N. S. Sariciftci, D. Moses, and A. J. Heeger, "Ultrafast spectroscopic studies of photoinduced electron-transfer from semiconducting polymers to $\mathrm{C}_{60}$," Phys. Rev. B, vol. 50, pp. 18543 $18552,1994$.

[38] B. P. Rand, J. G. Xue, S. Uchida, and S. R. Forrest, "Mixed donoracceptor molecular heterojunctions for photovoltaic applications. I. Material properties," J. Appl. Phys., vol. 98, p. 124902, 2005.

[39] A. Opitz, M. Bronner, and W. Brütting, "Ambipolar charge carrier transport in mixed organic layers of phthalocyanine and fullerene," $J$ Appl. Phys., vol. 101, p. 063709, 2007.

[40] M. A. Loi, C. Rost-Bietsch, M. Murgia, S. Karg, W. Rieß, and M. Muccini, "Tuning optoelectronic properties of ambipolar organic light- emitting transistors using a bulk-heterojunction approach," $A d v$. Funct. Mater, vol. 16, pp. 41-47, 2006.

[41] M. Bronner, A. Opitz, and W. Brütting, "Ambipolar charge carrier transport in organic semiconductor blends of phthalocyanine and fullerene," phys. stat. sol. (a), vol. 205, pp. 549-563, 2008.

[42] A. Opitz, M. Bronner, J. Wagner, M. Götzenbrugger, and W. Brütting, "Ambipolar organic semiconductor blends for photovoltaic cells," SPIE Proc., vol. 7002, p. 70020J, 2008

[43] A. Opitz, M. Bronner, W. Brütting, M. Himmerlich, J. A. Schaefer, and S. Krischok, "Electronic properties of organic semiconductor blends: ambipolar mixtures of phthalocyanine and fullerene," Appl. Phys. Lett., vol. 90, p. 212112, 2007.

[44] C. Uhrich, D. Wynands, S. Olthof, M. K. Riede, K. Leo, S. Sonntag B. Maennig, and M. Pfeiffer, "Origin of open circuit voltage in planar and bulk heterojunction organic thin-film photovoltaics depending on doped transport layers," J. Appl. Phys., vol. 104, p. 043107, 2008

[45] D. Wynands, B. Männig, M. Riede, K. Leo, E. Brier, E. Reinold, and P. Bäuerle, "Organic thin film photovoltaic cells based on planar and mixed heterojunctions between fullerene and a low bandgap oligothiophene," J. Appl. Phys., vol. 106, p. 054509, 2009.

[46] J. Nelson, J. Kirkpatrick, and P. Ravirajan, "Factors limiting the efficiency of molecular photovoltaic devices," Phys. Rev. B, vol. 69, p. 035337, 2004.

[47] P. Sullivan and T. Jones, "Pentacene/fullerene $\left(\mathrm{C}_{60}\right)$ heterojunction solar cells: Device performance and degradation mechanisms," Org. Electron., vol. 9, pp. 656-660, 2008

[48] A. Kumar, S. Sista, and Y. Yang, "Dipole induced anomalous S-shape I-V curves in polymer solar cells," J. Appl. Phys., vol. 105, p. 094512, 2009.

[49] M. Glatthaar, M. Riede, N. Keegan, K. Sylvester-Hvida, B. Zimmermann, M. Niggemann, A. Hinsch, and A. Gombert, "Efficiency limiting factors of organic bulk heterojunction solar cells identified by electrical impedance spectroscopy," Sol. Ener. Mater. Sol. Cell., vol. 91, p. 390393 , 2007.

[50] P. Peumans and S. R. Forrest, "Very-high-efficiency doubleheterostructure copper phthalocyanine/ $\mathrm{C}_{60}$ photovoltaic cells," Appl. Phys. Lett., vol. 79, pp. 126-128, 2001.

[51] P. Peumans, V. Bulović, and S. R. Forrest, "Efficient photon harvesting at high optical intensities in ultrathin organic double-heterostructure photovoltaic diodes," Appl. Phys. Lett., vol. 76, pp. 2650-2652, 2000.

[52] N. Li, B. E. Lassiter, R. R. Lunt, G. Wei, and S. R. Forrest, "Open circuit voltage enhancement due to reduced dark current in small molecule photovoltaic cells," Appl. Phys. Lett., vol. 94, p. 023307, 2009.

[53] H. Gommans, B. Verreet, B. P. Rand, R. Muller, J. Poortmans, P. Heremans, and J. Genoe, "On the role of bathocuproine in organic photovoltaic cells," Adv. Funct. Mater., vol. 18, pp. 3686-3691, 2008.

[54] J. Meiss, M. K. Riede, and K. Leo, "Optimizing the morphology of metal multilayer films for indium tin oxide ITO-free inverted organic solar cells," J. Appl. Phys., vol. 105, p. 063108, 2009.

[55] M. Knupfer and H. Peisert, "Electronic properties of interfaces between model organic semiconductors and metals," phys. stat. sol. (a), vol. 201, pp. 1055-1074, 2004.

[56] H. Brinkmann, C. Kelting, S. Makarov, O. Tsaryova, G. Schnurpfeil, D. Wöhrle, and D. Schlettwein, "Fluorinated phthalocyanines as molecular semiconductor thin films," phys. stat. sol. (a), vol. 205, pp. 409-420, 2008.
[57] A. Opitz, B. Ecker, J. Wagner, A. Hinderhofer, F. Schreiber, J. Manara, J. Pflaum, and W. Brütting, "Mixed crystalline films of co-evaporated hydrogen- and fluorine-terminated phthalocyanines and their application in photovoltaic devices," Org. Electron., vol. 10, pp. 1259-1267, 2009.

[58] I. Salzmann, S. Duhm, G. Heimel, J. P. Rabe, N. Koch, M. Oehzelt, Y. Sakamoto, and T. Suzuki, "Structural order in perfluoropentacene thin films and heterostructures with pentacene," Langmuir, vol. 24, pp. 7294-7298, 2008.

[59] J.-O. Vogel, I. Salzmann, R. Opitz, S. Duhm, B. Nickel, J. P. Rabe, and N. Koch, "Sub-nanometer control of the interlayer spacing in thin films of intercalated rodlike conjugated molecules," J. Phys. Chem. B, vol. 111, pp. 14097-14 101, 2007

[60] M. Kröger, S. Hamwi, J. Meyer, T. Dobbertin, T. Riedl, W. Kowalsky, and H.-H. Johannes, "Temperature-independent field-induced charge separation at doped organic/organic interfaces: Experimental modeling of electrical properties," Phys. Rev. B, vol. 75, p. 235321, 2007.

[61] A. Facchetti, "Semiconductors for organic transistors," Mater. Today, vol. 10, pp. 28-37, 2007.

[62] S. Yoo, B. Domercq, and B. Kippelen, "Efficient thin-film organic solar cells based on pentacene/ $\mathrm{C}_{60}$ heterojunctions," Appl. Phys. Lett., vol. 85, pp. 5427-5429, 2004.

[63] A. K. Pandey and J.-M. Nunzi, "Efficient flexible and thermally stable pentacene/ $\mathrm{C}_{60}$ small molecule based organic solar cells," Appl. Phys. Lett., vol. 89, p. 213506, 2006

[64] A. C. Dürr, F. Schreiber, M. Münch, N. Karl, B. Krause, V. Kruppa, and $\mathrm{H}$. Dosch, "High structural order in thin films of the organic semiconductor diindenoperylene," Appl. Phys. Lett., vol. 81, pp. 22762278, 2002.

[65] R. Resel, N. Koch, F. Meghdadi, G. Leising, W. Unzog, and K. Reichmann, "Growth and preferred crystallographic orientation of hexaphenyl thin films," Thin solid films, vol. 305, pp. 232 - 242, 1997.

[66] B. Servet, S. Ries, M. Trotel, P. Alnot, G. Horowitz, and F. Garnier, "X-ray determination of the crystal structure and orientation of vacuum evaporated sexithiophene films," Adv. Mater., vol. 5, pp. 461-464, 1993.

[67] D. Fujishima, H. Kanno, T. Kinoshita, E. Maruyama, M. Tanaka, M. Shirakawa, and K. Shibata, "Organic thin-film solar cell employing a novel electron-donor material," Sol. Ener. Mater. Sol. Cell., vol. 93, pp. $1029-1032,2009$.

[68] A. K. Tripathi and J. Pflaum, "Correlation between ambipolar transport and structural phase transition in diindenoperylene single crystals," Appl. Phys. Lett., vol. 89, p. 082103, 2006.

[69] D. Kurrle and J. Pflaum, "Exciton diffusion length in the organic semiconductor diindenoperylene," Appl. Phys. Lett., vol. 92, p. 133306, 2008.

[70] R. R. Lunt, J. B. Benziger, and S. R. Forrest, "Relationship between crystalline order and exciton diffusion length in molecular organic semiconductors," Adv. Mater, published online.

[71] J. Wagner, M. Gruber, A. Opitz, W. Brütting, and J. Pflaum, "High fill factor and open circuit voltage in organic solar cells employing the donor material diindenoperylene," in preparation.

[72] B. P. Rand, D. P. Burk, and S. R. Forrest, "Offset energies at organic semiconductor heterojunctions and their influence on the open-circuit voltage of thin-film solar cells," Phys. Rev. B, vol. 75, p. 115327, 2007.

[73] S. Veenstra, G. Malliaras, H. Brouwer, F. Esselink, V. Krasnikov, P. van Hutten, J. Wildeman, H. Jonkman, G. Sawatzky, and G. Hadziioannou, "Sexithiophene- $\mathrm{C}_{60}$ blends as model systems for photovoltaic devices," Synthetic Met., vol. 84, pp. 971 - 972, 1997.

[74] S. Alem, A. K. Pandey, K. N. N. Unni, J.-M. Nunzi, and P. Blanchard, "Molecular model T6: $\mathrm{C}_{60}$ bulk-heterojunction solar cells," J. Vac. Sci. Technol. A, vol. 24, pp. 645-648, 2006.

[75] J. Zhang, I. Salzmann, S. Rogaschewski, J. P. Rabe, N. Koch, F. Zhang, and $\mathrm{Z}$. Xu, "Arrays of crystalline $\mathrm{C}_{60}$ and pentacene nanocolumns," Appl. Phys. Lett., vol. 90, p. 193117, 2007.

[76] M.-S. Kim, J.-S. Kim, J. C. Cho, M. Shtein, L. J. Guo, and J. Kim, "Flexible conjugated polymer photovoltaic cells with controlled heterojunctions fabricated using nanoimprint lithography," Appl. Phys. Lett., vol. 90, p. 123113, 2007.

[77] D. Cheyns, K. Vasseur, C. Rolin, J. Genoe, J. Poortmans, and P. Heremans, "Nanoimprinted semiconducting polymer films with $50 \mathrm{~nm}$ features and their application to organic heterojunction solar cells," Nanotechnology, vol. 19, p. 424016, 2008. 


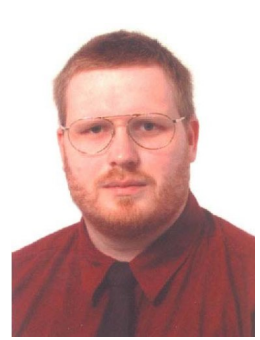

Andreas Opitz received his $\mathrm{PhD}$ in physics from the Technical University of Ilmenau in 2003. Afterwards he went to the University of Augsburg working on charge carrier transport in organic semiconductors focused on field-effect transistors and photovoltaic cells using molecular and polymeric materials. His current research is related to the charge transport, injection and separation properties at organic/organic and organic/inorganic interfaces. In 2009 he became lecturer for Experimental Physics.

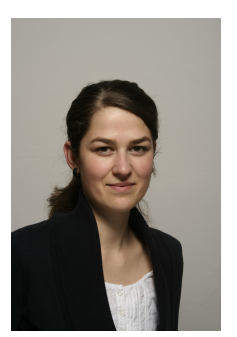

Julia Wagner studied Material Science at the University of Augsburg. Since 2008 she works as Ph.D. student in the group of Prof. Brütting. Her research focuses on charge transport and device performance of organic solar cells based on small molecules.

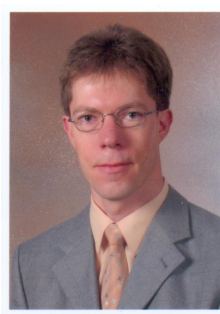

Wolfgang Brütting received his $\mathrm{PhD}$ in Physics from the University of Bayreuth in 1995 with a work on charge transport in one-dimensional chargedensity wave systems. He then moved to the field of organic semiconductors where he could take part in the development of organic light-emitting devices for display applications.

In 2003 he became Professor for Experimental Physics at the University of Augsburg. His research interests are the physics of organic semiconductors, including thin film growth, photophysics and electrical transport of these materials and the related electronic devices.

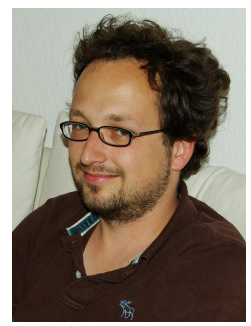

Ingo Salzmann studied physics at the Graz University of Technology in Austria and received his $\mathrm{PhD}$ at the Humboldt-Universität zu Berlin (Germany) in 2008 in the groups of Jürgen P. Rabe and Norbert Koch, where is currently post-doctoral research associate. His research focuses on structureenergetic correlations in thin organic films regarding applications in organic electronics, mainly using $\mathrm{x}$ ray scattering techniques and photoelectron spectroscopy as experimental tools.

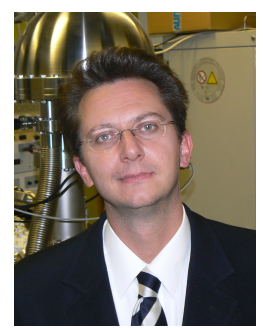

Norbert Koch studied physics at the Graz University of Technology in Austria and received his $\mathrm{PhD}$ in 2000. Until 2002 he was post-doctoral researcher at Princeton University (USA), then worked as research associate in the group of Jürgen P. Rabe at Humboldt-Universität zu Berlin (Germany) and headed a junior research group in the Emmy Noether Program (DFG) from 2004-2009. Since 2009 he is full professor at Humboldt-Universität. His work focuses on the electronic and structural properties of complex functional interfaces with organic materials, and the exploration of new strategies for organic-organic and organic-inorganic heterostructure fabrication.

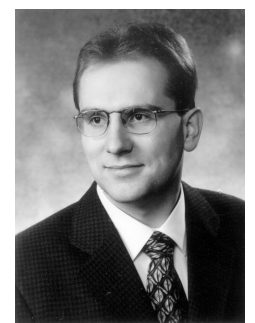

Jochen Manara studied physics at the JuliusMaximilians-University Würzburg and received his $\mathrm{PhD}$ in 2001. In 2002 he became manager of the Applied IR Metrology group at ZAE Bayern. His current research focuses on the optical and infraredoptical characterization of solids and thin films. This includes the analytical and numerical modeling of radiative transfer through materials and between surfaces.

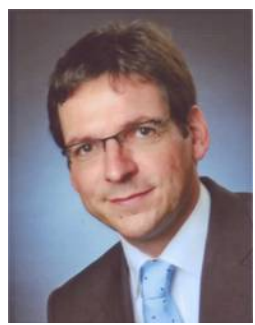

Jens Pflaum is an expert for molecular solid-state physics. He received his PhD from Bochum University in 1999 followed by a post-doctoral fellowship at Princeton University. He continued research on transport phenomena in organic crystals at Stuttgart University 2001-2008. In 2008 he became professor at Würzburg University and group leader of the Organic Photovoltaics and Electronics division at the ZAE Bayern with focus on molecular optoelectronics.

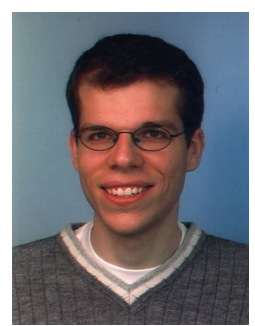

Alexander Hinderhofer studied physics at the Eberhard-Karls-University of Tübingen. Since 2007 he is PhD student at the Institute of Applied Physics of the University of Tübingen in the group of Prof. Schreiber. His research focuses on the optical and structural characterization of organic heterostructure interfaces in real time during growth.

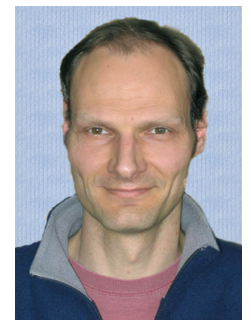

Frank Schreiber obtained his PhD from Bochum University in 1995. After a post-doctoral stay in Princeton he moved to Stuttgart (Max Planck institute and university) in 1997 to lead the organic thin films group. In 2002-2004 he was a University lecturer in Oxford, UK, after which he became a full professor at the University of Tübingen. His group is working on the physics of molecular and biological matter. 